\title{
Hypnosis and progressive muscle relaxation for anxiolysis and pain control during extraction procedure in 8-12-year-old children: a randomized control trial
}

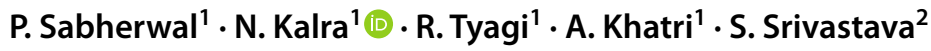

Received: 27 October 2020 / Accepted: 17 March 2021 / Published online: 29 March 2021

(c) European Academy of Paediatric Dentistry 2021

\begin{abstract}
Introduction Hypnosis (H) and Progressive Muscle Relaxation (PMR) have proven to be effective in a variety of medical settings; there is a paucity of their practical application in paediatric dentistry. The study aimed to comparatively evaluate the role of $\mathrm{H}$ and PMR on anxiety, heart rate (HR), oxygen saturation $\left(\mathrm{SPO}_{2}\right)$, blood pressure (BP), pain, and analgesic requirement during extraction in children.

Materials and methods Sixty children aged 8-12 years undergoing primary molar extractions were randomly allocated to three groups- $\mathrm{H}$, PMR, and control (C). The anxiety (proposed Visual Facial Anxiety scale), HR, and $\mathrm{SPO}_{2}$ were measured pre/post-operatively with/without interventions (H, PMR, C) at 4 intervals. The BP and pain (Wong-Baker faces pain scale) were recorded pre- and post-operatively. Need for analgesic post-operatively was assessed.

Results Statistically significant reduction in anxiety was noted post-extraction in $\mathrm{H}(0.30 \pm 0.80)$, PMR $(0.50 \pm 0.69)$ $(p<0.001 *)$. HR showed a statistically significant drop after H, PMR application. $(p<0.001 *)$ No significant difference in $\mathrm{SPO}_{2}$ was noted in the three groups $(p>0.05)$. Pain control was well achieved using $\mathrm{H}(85 \%)$, PMR (70\%); BP was wellregulated in the H, PMR compared to C group $(p<0.001 *)$. Need for analgesics was reduced in $\mathrm{H}(45 \%)$, PMR $(50 \%)$ versus C (100\%). Both techniques H, PMR were comparable in all measures.

Conclusion Hypnosis and PMR are effective techniques for anxiolysis and pain control in paediatric dental patients.
\end{abstract}

Keywords Hypnosis · Progressive muscle relaxation · Anxiety · Pain · Oxygen saturation

Namita Kalra was formerly at Head of Faculty of Dentistry, Univerity of Delhi. Member of the academic council of University of Delhi, Member of the National Academy of Medical Sciences, India.

\section{Introduction}

Anxiety and pain are subjective experiences that make dental treatment difficult for children especially during the time of anaesthesia leading to distress, postponements, and compromised oral health (Glaesmer et al. 2015; RamirezCarrasco et al. 2017). Pain and anxiety are inter-related as pain involves emotional and sensorial components (Armfield

1 Department of Pedodontics and Preventive Dentistry, University College of Medical Sciences, Guru Teg Bahadur Hospital University of Delhi, New Delhi 110095, Delhi, India

2 Department of Psychiatry, University College of Medical Sciences, Guru Teg Bahadur Hospital University of Delhi, New Delhi 110095, Delhi, India

A. Khatri

khatri9084@redifmail.com

S. Srivastava

srivastava_shruti@hotmail.com 
and Heaton 2013). To manage anxiety/pain, some advocate the use of deep sedation or intravenous/inhalational sedation (Zanette et al. 2007). The use of pharmacological measures, however, requires the use of expensive armamentarium requiring time and manpower (Jameson et al. 2007), has associated risks and side-effects (Calipel et al. 2005) and requires thorough monitoring, management, and documentation (Jameson et al. 2007). Numerous non-pharmacological interventions to allay anxiety/pain have also been advocated. The use of communication skills, rapport building, and tellshow-do technique are common psychotherapeutic interventions used in the dental clinic but with limited success (Appukuttan 2016).

Hypnosis and Progressive Muscle Relaxation have proven to have anxiety/pain resolving effects in a variety of medical and psychiatric settings. Hypnosis was noted to be effective in reducing perioperative discomfort of conscious sedation (Faymonville et al. 1998) and to help patients suffering from chronic dyspnoea (Anbar 2001). PMR has been found to be helpful in managing anxiety in patients of Generalized Anxiety Disorders, Panic disorders (Conrad and Roth 2007) and raising the nociceptive flexion reflex threshold (Emery et al. 2008). In paediatric dentistry, hypnosis has been successful in reducing physical resistance, HR among children receiving local anaesthesia for pulp therapy (Oberoi et al. 2016) and reducing subjective anxiety/pain among children undergoing tooth extractions (Huet et al. 2011). PMR was observed to be effective in reducing anxiety, HR and BP among periodontal surgery adult patients (Park et al. 2019).

Both techniques are holistic, requiring limited manpower and armamentarium (Appukuttan 2016). To the best of the knowledge of the researchers, no existing studies focus on drawing a comparison between hypnosis and PMR on dental anxiety/pain relief in paediatric patients undergoing extractions (Al-Harasi et al. 2010; Oberoi et al. 2016; Park et al. 2019). The purpose of the present study was to comparatively evaluate the effects of Hypnosis and Progressive Muscle Relaxation on anxiety and pain in paediatric tooth extraction procedures using subjective, objective haematological measures.

\section{Methods}

\section{Study design}

The Randomized control trial was conducted from November 2018 to April 2020 on 8-12-year-old children undergoing primary molar extractions.

\section{Ethical considerations}

The study was carried out in accordance with 1964 Helsinki Declaration and its later amendments or comparable ethical standards. Ethical approval was obtained from the Institutional Ethics Committee-IEC-HR/2018/36/133 dated $15 / 10 / 2018$. The purpose and nature of the study were explained to parents and children. Informed consent was obtained including parental consent and paediatric assent in the native language i.e. Hindi.

\section{Sample size estimation}

Based on literature with similar study methodology (Huet et al. 2011), considering MYPAS anxiety at the time of anaesthesia, 12/14 and 5/15 subjects had a score less than 30 in the Hypnotic group versus Non-Hypnotic group. To estimate this difference at alpha 5\%, Power $80 \%$ and confidence interval (CI) $95 \%$, a sample size of 13 was required per group. Considering a variability of 2.16 and 1.05 in NonHypnosis versus Hypnosis group, to estimate a difference of 1.8 units of post-operative pain at alpha 5\%, Power $80 \%$ and CI 95\%, a sample size of 14 was required per group. To account for Bonferroni corrections, we inflated the sample size by $30 \%$, i.e. 20 per group.

\section{Study population and inclusion criteria}

Children included were in the age range of $8-12$ years; requiring extraction of one primary molar (Alsheneifi and Hughes 2001) as first dental intervention. Teeth indicated for extraction comprised of primary molars indicated for extraction due to sequelae of advanced dental caries such as sinus, pathological resorption (greater than one-third of root length), pulpal floor perforation or grossly destroyed/ unrestorable crown structure. Over-retained molars up to Grade-I mobility were included. All children who had pre-operative anxiety above mild on the proposed Visual Facial Anxiety Scale (VFAS) (Cao et al. 2017) were considered. Children who had known allergy to local anaesthesia, or specific medical illnesses/psychological impairments and children/parents who were not willing to participate were excluded from the study. Teeth with associated extra-oral swelling, mobility (Grade II/III) or traumatic dental injury were excluded to minimize bias in pain levels post-extraction.

\section{Randomization}

Simple-random sampling technique was used where computer-generated random numbers were used to allocate children into three groups-Hypnosis (group I), Progressive 
Muscle Relaxation (group II) and Control (group III). After meeting the inclusion criteria considerations, children were assigned to groups by an evaluator (RT) blinded to the study interventions.

\section{Interventions and operator training}

For hands-on training, the investigator underwent training in the techniques, history taking, mental state examination, and identification of common mental disorders under a trained Psychiatrist. The investigator underwent university-level training in hypnotherapy and obtained a diploma in Hypnotherapy which is nationally accredited by American Hypnosis Association. All behavioural interventions (Hypnosis, PMR) were performed by a single trained post-graduate (PS) under the supervision of a qualified Psychiatrist (SS). The anaesthesia administration and tooth extraction procedures were done by a post-graduate student (PS) under the supervision of experienced paediatric dentists (NK, AK). The records of subjective anxiety (VFAS) and physiological measurements (HR, $\mathrm{SPO}_{2}$, BP) were made by an experienced paediatric dentist (RT) who was blinded to the study groups being assessed. The step-wise summary of study design as per CONSORT Guidelines for Social and Psychological Interventions (Montgomery et al. 2018) is illustrated in Fig. 1.

\section{Hypnotic technique}

The hypnotic technique was primarily adapted for children undergoing dental extractions and uses only initial levels of hypnosis for the relaxation of the child. The child was asked to focus on a point in the wall followed by focused inhalations-exhalations (5-10 times). This was followed by the reverse count induction technique after which the clinician lightly touched the middle of the child's forehead and used the words 'Deep Sleep'. A sequence of relaxation suggestions for various body parts from the tip of the toes to the top of the head were delivered. Afterwards, the child was told to imagine or visualize a safe happy place like seaside, playground or festival. The count from 1-5 was done to wake the child to restful conscious awareness. The procedure used for Hypnotic induction is based on Axelrad et al. (2009) and Kohen et al. (2011) before anaesthesia administration as illustrated in Fig. 2.

\section{Progressive muscle relaxation}

The technique of PMR used was adapted for children wherein the child was asked to close his/her eyes and inhale-exhale ( $* 5$ times). This was followed by series of suggestions to tense and relax target muscle groups scripted for children to easily understand. For instance, the child was asked to imagine holding and squeezing an orange in each hand (count 1-5) followed by releasing any tension and letting the orange fall down (count 5-0). The step-wise procedure in the PMR technique is based on Karasu et al. (2009) and modified for children as per Children's Anxiety Institute (2018) as illustrated in Fig. 3.

\section{Control group}

To minimize bias from the placebo controls (Baskin et al. 2003), communication and rapport building along with tender, love and care was done with each child in the control group to spend time with the child pre-procedurally. This was deemed suitable as the control intervention as use of communication and rapport building are age-old day to day practices in the extraction room particularly for young patients (Chambers 1976).

\section{Anaesthesia technique}

After application of topical anaesthesia (2\% lignocaine gel), 2\% lignocaine with 1:1,00,000 epinephrine (Kwality Pharmaceuticals Ltd., Amritsar-India) was administered. For maxillary molars, local buccal infiltration $(27 \mathrm{G}$, short needle) at the height of the mucobuccal fold and palatal infiltration, 5-10 $\mathrm{mm}$ from free gingival margin was carried out. For mandibular molars, inferior alveolar nerve block anaesthesia (25G, long needle) was deposited while placing thumb at the coronoid notch and penetrating three-fourths the antero-posterior distance from the coronoid notch to the deepest part of the pterygomandibular raphe. Slow delivery of anaesthetic in fractioned doses in the range of $0.6-1.8 \mathrm{ml}$ depending on the child's size and body weight (maximum $7 \mathrm{mg} / \mathrm{kg}$ ) was done after aspiration.

\section{Outcome measures}

The primary outcomes were the subjective anxiety levels using VFAS and objective anxiety measures i.e. heart rate, oxygen saturation, blood pressure and pain levels. The selfreported proposed VFAS was used in the present study for subjective anxiety assessment at four defined intervals i.e. baseline, after the intervention, after local anaesthesia and extraction (scores assigned: $0-5$ ). The proposed VFAS by Cao et al. (2017) is a simple six-point ordinal scale representing a growing level of anxiety from 'none' shown by neutral facial expression to 'highest' shown by face displaying excessive fear. The proposed VFAS is a new tool for subjective anxiety measurement, which is valid with strengthened construct validity to assess acute anxiety in busy operative settings.

Pulse oximeter (Pulse Oximeter, PO-15, Delhi, India) was used to record oxygen saturation and heart rate at four 


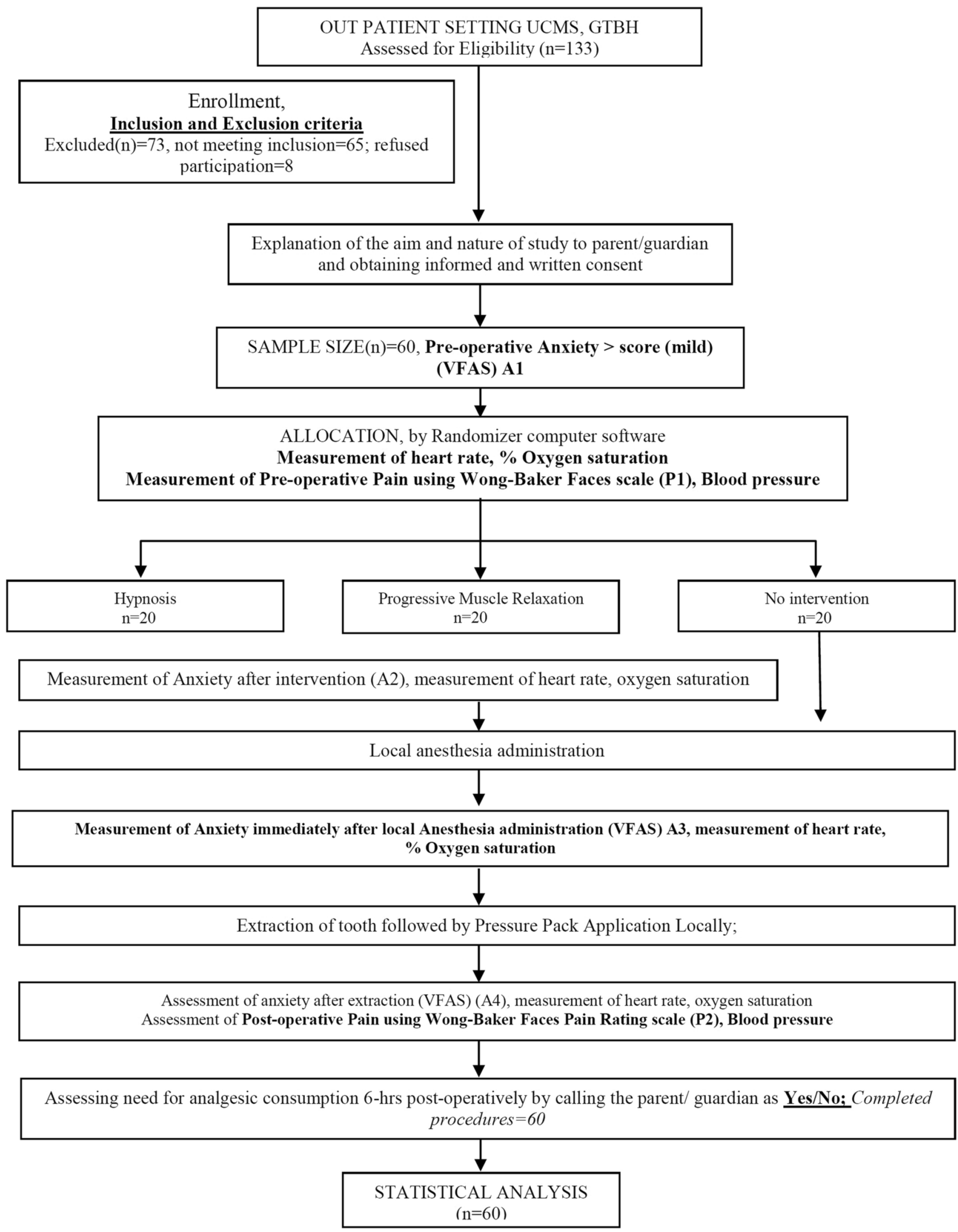

Fig. 1 Step-wise illustration of the study methodology 
Fig. 2 Step-wise illustration of the Hypnotic technique used in the study based on Axelrad et al. (2009) and Kohen et al. (2011)

Fig. 3 Step-wise illustration of Progressive Muscle Relaxation technique used based on Karasu et al. (2009) and modified for children as per Children's Anxiety Institute (2018)
Focus on one point, hold breath for $5 \mathrm{~s}$ followed by exhaling (5-10 times)

\begin{tabular}{|}
$\begin{array}{c}\text { Close eyes and begin reverse count from 50, at random intervals clinician snapped his/her } \\
\text { fingers and ask patient to go one number up from the current count }\end{array}$ \\
$\begin{array}{c}\text { On reaching 0, clinician lightly touches middle of the patient's forehead and uses the words } \\
\text { 'Deep Sleep' }\end{array}$ \\
and relaxed place eg. Birthday party, playground, festival, sea side \\
Count to 5 and the patient was asked to open eyes slowly.
\end{tabular}

Patient was told to close his/her eyes, inhale deeply from nose and exhale deeply from mouth $(* 5$ times $)$

$\downarrow$

The patient was told to draw awareness to muscles of face and slowly relax the jaw, shoulders, and tummy and observe the rise and fall of tummy with breathing

\begin{tabular}{|c|}
\hline $\begin{array}{c}\text { Relaxation instructions were read as follows-Imagine you are holding an orange in your } \\
\text { right hand, squeeze it tightly for } 5 \mathrm{~s}(1,2,3,4,5) \text { and then release (Repeat for Left Hand })\end{array}$ \\
\hline Now stretch both your arms high above to the ceiling/ sky, higher with each count \\
\hline Now imagine you are chewing a gum/toffee; Chew $(1,2,3,4,5)$ Now relax \\
\hline Now suck in your breath just like you do when you want to look thin; Hold (1,2,3,4,5) Now \\
Release \\
\hline Now muscles of your face exactly as you do when you are angry; Hold \\
\hline Nourself walking on sand, squeeze your toes as if you are walking, now relax \\
\hline \\
\hline
\end{tabular}


defined intervals as above-mentioned. An automated blood pressure monitor (MX3; Omron, Tokyo, Japan) was used to record blood pressure pre- and post-extraction procedure.

The pain levels using the Wong-Baker Faces Pain Rating Scale (WBS) were also assessed pre and post-extraction as a primary study outcome. The WBS developed by Donna Wong and Connie Baker shows a series of faces ranging from a happy face at 0 to a crying face at 10 was used (Wong and Baker 1988). For post-extraction pain control, Ibuprofen $(5 \mathrm{mg} / \mathrm{kg} / \mathrm{dose})$ spaced apart minimum 6-8 hourly as required was prescribed. As a secondary study outcome, the post-operative need for analgesic consumption was assessed for each child by telephonic communication with parent/ guardian after $6 \mathrm{~h}$ of the procedure and ascertained as yes or no answers.

\section{Statistical analysis}

The data were entered into Microsoft Excel (2016) and analysed using SPSS (Statistical Package for Social Sciences, SPSS version 26.0 IBM INC., USA). Repeated measures ANOVA test with post-hoc Bonferroni test was used for the comparison of parametric continuous data. Kruskal-Wallis test with Mann-Whitney $U$ test was used for comparing anxiety between different groups. A $p$ value of 0.05 or less was considered to be statistically significant.

\section{Results}

The study composed of 60 children i.e. 36 males and 24 females with mean age of 9.75 years who were randomly allocated to three groups i.e. $\mathrm{H}$ group (13 males, 7 females; mean age 10.60 years), PMR (11 males, 9 females; mean age 9.05 years) and $C$ group ( 12 males, 8 females; mean age 9.60 years). The teeth extracted were a total of 33 mandibular molars and 27 maxillary molars distributed randomly among the groups. The variables recorded were anxiety, heart rate, partial pressure oxygen, blood pressure, pain, and need for analgesic measured at definite intervals from baseline to post-extraction procedure.
Table 1 depicts the inter-group comparison of anxiety analysed using Kruskal-Wallis and Mann-Whitney $U$ test showing significant fall in anxiety after local anaesthesia $\left(p<0.001^{*}\right)$ when H, PMR were applied. There was a significant anxiety reduction in $\mathrm{H}(0.30 \pm 0.80)$ and PMR group $(0.50 \pm 0.69)$ post-extraction $(p<0.001 *)$. The control group showed a rise in anxiety after local anaesthesia $(3.45 \pm 1.47)$ and post-extraction $(3.35 \pm 1.39)$ $\left(p<0.001^{*}\right)$.

After $\mathrm{H}$, anxiety scores decreased to $81 \%$ of mean baseline value. In the $\mathrm{H}$ group, children with anxiety below baseline scores after local anaesthesia and extraction were 90\% (18 of 20) and 95\% (19 of 20) respectively. After PMR, scores declined to $74 \%$ of mean baseline anxiety score and $100 \%$ children ( 20 of 20 ) had anxiety below baseline after local anaesthesia and extraction. In the $\mathrm{C}$ group, scores increased significantly after local anaesthesia and extraction in $75 \%$ (15 of 20) and $80 \%$ of children (16 of 20) respectively. Post administration of local anaesthesia, anxiety scores were found to increase compared to post-intervention scores in 30\% children ( 6 of 20) in both $\mathrm{H}$ and PMR groups.

Table 2 depicts the inter-group comparison of $\mathrm{HR}, \mathrm{SPO}_{2}$, and BP using one-way ANOVA and post-hoc Bonferroni tests. The mean HR post-extraction was found to drop by 22 points in the $\mathrm{H}$ group, 20 points in the PMR group and rise by 13 points in the $\mathrm{C}$ group $(p<0.001 *)$. No significant difference in oxygen saturation was observed among the three groups $(p>0.05)$. Mean systolic BP was found to rise by 12 units, mean diastolic BP showed a rise of 5 units in the C group $(p<0.001 *)$ whereas no significant difference was observed in H, PMR groups $(p>0.05)$.

Figure 4 depicts comparison of pain among the three groups using one-way ANOVA and post-hoc Bonferroni tests. Statistically, significant pain reduction was seen in $\mathrm{H}(1.30 \pm 1.63)$, PMR $(1.80 \pm 2.42)$ groups post-extraction $(p<0.001 *)$. The $\mathrm{C}$ group demonstrated a rise in pain $(4.80 \pm 2.46)(p<0.001 *)$. Good pain control post-extraction was noted in $85 \%$ children (17 of 20 ) in $\mathrm{H}$ group, $70 \%$ of children (14 of 20) in PMR group whereas $\mathrm{C}$ group showed poor control of pain in $90 \%$ children (18 of 20). All 20 children $(100 \%)$ needed analgesic post-operatively in the control

Table 1 Inter-group variation of anxiety scores at three intervals namely preoperatively, after local anaesthesia, and after extraction

\begin{tabular}{llllrrrr}
\hline Time for recording anxiety & $\begin{array}{l}\text { Hypnosis (I) } \\
\text { Mean } \pm \text { SD }\end{array}$ & $\begin{array}{l}\text { PMR (II) } \\
\text { Mean } \pm \text { SD }\end{array}$ & $\begin{array}{l}\text { Control (III) } \\
\text { Mean } \pm \text { SD }\end{array}$ & $p$ value $^{\mathrm{a}}$ & I vs II $^{\mathrm{b}}$ & I vs III $^{\mathrm{b}}$ & II vs III $^{\mathrm{b}}$ \\
\hline Baseline & $2.65 \pm 1.14$ & $2.85 \pm 1.39$ & $2.25 \pm 1.37$ & 0.340 & 1.000 & 1.000 \\
After local anaesthesia & $0.75 \pm 1.16$ & $0.80 \pm 1.06$ & $3.45 \pm 1.47$ & $<0.001^{*}$ & 1.000 & $<0.453$ \\
After extraction & $0.30 \pm 0.80$ & $0.50 \pm 0.69$ & $3.35 \pm 1.39$ & $<0.001^{*}$ & 1.000 & $<0.001^{*}$ \\
\hline
\end{tabular}

$P M R$ progressive muscle relaxation, $I$ hypnosis, II progressive muscle relaxation, III control

${ }^{\mathrm{a}}$ Kruskal-Wallis test, ${ }^{\mathrm{b}}$ Mann-Whitney $U$ test

* Significant difference 
Table 2 Depicting variation of heart rate, partial pressure oxygen, blood pressure among the three groups at various intervals

\begin{tabular}{|c|c|c|c|c|c|c|c|c|}
\hline Variable & Interval & $\begin{array}{l}\text { Hypnosis (I) } \\
\text { Mean } \pm \text { SD }\end{array}$ & $\begin{array}{l}\text { PMR (II) } \\
\text { Mean } \pm \text { SD }\end{array}$ & $\begin{array}{l}\text { Control (III) } \\
\text { Mean } \pm \text { SD }\end{array}$ & $p$ value $^{\mathrm{a}}$ & I vs II ${ }^{b}$ & I vs III' & II vs III ${ }^{\mathrm{b}}$ \\
\hline \multirow[t]{3}{*}{$\mathrm{HR}$} & Baseline & $120.70 \pm 15.33$ & $121.75 \pm 12.24$ & $112.90 \pm 9.38$ & 0.059 & 1.000 & 0.061 & 0.055 \\
\hline & After local anaesthesia & $98.50 \pm 15.73$ & $101.55 \pm 11.98$ & $125.90 \pm 22.75$ & $<0.001 *$ & 1.000 & $<0.001^{*}$ & $<0.001 *$ \\
\hline & After extraction & $91.50 \pm 12.42$ & $95.75 \pm 10.13$ & $127.55 \pm 22.15$ & $<0.001 *$ & 1.000 & $<0.001 *$ & $<0.001^{*}$ \\
\hline \multirow[t]{3}{*}{$\mathrm{SPO}_{2}$} & Baseline & $98.40 \pm 1.47$ & $97.25 \pm 2.36$ & $98.80 \pm 0.95$ & 0.055 & 0.109 & 1.000 & 0.056 \\
\hline & After local anaesthesia & $98.05 \pm 1.19$ & $97.75 \pm 1.21$ & $97.90 \pm 2.02$ & 0.825 & 1.000 & 1.000 & 1.000 \\
\hline & After extraction & $98.15 \pm 1.63$ & $98.20 \pm 1.06$ & $97.55 \pm 1.28$ & 0.243 & 1.000 & 1.000 & 1.000 \\
\hline \multirow[t]{2}{*}{ Systolic BP } & Baseline & $126.40 \pm 10.12$ & $126.20 \pm 10.02$ & $122.95 \pm 7.94$ & 0.434 & 1.000 & 0.754 & 0.839 \\
\hline & Post-operatively & $122.80 \pm 4.51$ & $123.30 \pm 6.78$ & $135.20 \pm 7.38$ & $<0.001^{*}$ & 1.000 & $<0.001^{*}$ & $<0.001^{*}$ \\
\hline \multirow[t]{2}{*}{ Diastolic BP } & Baseline & $79.75 \pm 5.87$ & $79.85 \pm 5.85$ & $79.40 \pm 5.61$ & 0.967 & 1.000 & 1.000 & 1.000 \\
\hline & Post-operatively & $79.50 \pm 4.35$ & $78.80 \pm 4.83$ & $84.55 \pm 5.29$ & $0.001 *$ & 1.000 & $0.005^{*}$ & $0.001 *$ \\
\hline
\end{tabular}

$P M R$ progressive muscle relaxation; $H R$ heart rate; $\mathrm{SPO}_{2}$ oxygen saturation; $\mathrm{BP}$ blood pressure

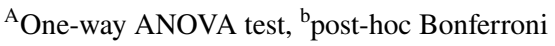

* Significant difference

Fig. 4 Variation in pain scores at two intervals namely preand post-operatively in the three groups. (I-H; II-PMR; III-C)

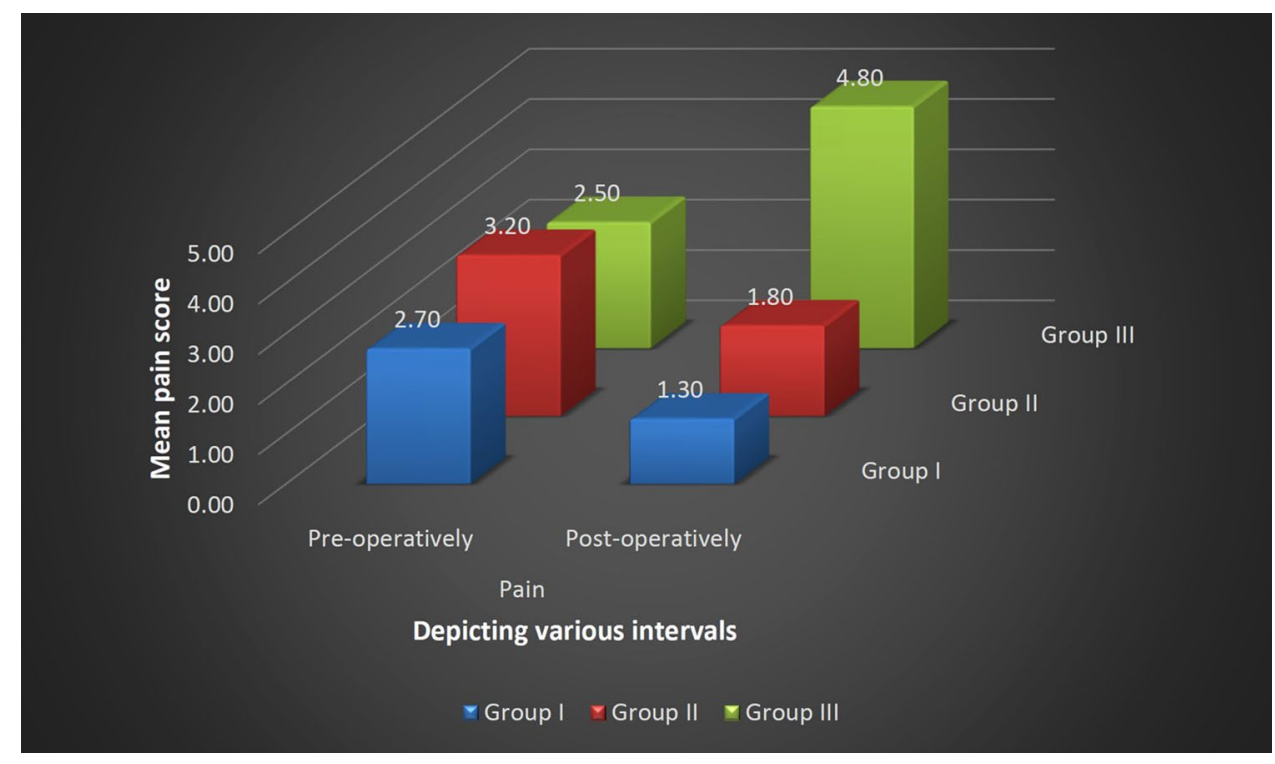

group. H, PMR showed the reduced requirement of analgesic to $45 \%$ and $50 \%$ respectively.

\section{Discussion}

The effect of Hypnosis, Progressive Muscle Relaxation, and the control group on anxiety/pain in children undergoing extraction procedure was studied in-depth on a comparative single-blinded basis. Tooth extractions are the most likely procedure to induce fear/pain in a child (Klaassen et al2008), therefore the study inclusion incorporated only children undergoing extraction procedures. A significant fall in anxiety and pain measures was observed when $\mathrm{H}, \mathrm{PMR}$ were employed.
Hypnosis was successful in resolving anxiety and the low anxiety state continued to be maintained till the end of the procedure with a long, calming effect. The findings were similar to a study by Huet et al. (2011) where the modified Yale Preoperative Anxiety Scale score was 50\% lower in the Hypnosis group. A study by Oberoi et al. (2016) studied anxiety in 6-16-year-old children receiving dental anaesthesia with and without hypnosis and found significantly lower resistance in the hypnosis group. Similarly, Gokli et al. (1994) reported less crying in children receiving local anaesthesia under hypnosis.

A study by Calipel et al. (2005) compared hypnosis with midazolam in 2-11-year-old children undergoing surgery and revealed lower anxiety for hypnosis. Our findings were contrary to Ramirez-Carrassco et al. (2017) where the Faces, 
Legs, Activity, Cry, and Consolability was used to assess anxiety during anaesthesia and found no significant differences. The probable reason could be the use of audiotape for hypnosis rather than personal interaction.

Likewise, Progressive Muscle Relaxation was successful in resolving anxiety with a long-calming effect on children. Our findings were similar to study by Park et al. (2019) where reduced anxiety was appreciated in PMR group during periodontal surgery. Berggren et al. (2000) found relaxation therapies to be effective in reducing anxiety among fearful patients.

On the contrary, in the control group, a considerable rise in anxiety was recorded. 'Belonephobia' or the fear of injection is the most common reason for dental apprehension in both children and adults (Armfield and Heaton 2013). Throughout the study, we observed that local anaesthesia was an unpleasant stimulus for children.

Further, three patients each in Hypnosis and PMR group were found to be low responders. This may be attributed to variable suggestibility of children to hypnosis (Huet et al. 2011) and requires further studies to understand the nature of resistance. Two patients in the control group showed complete resolution of anxiety. The nature of behaviour was unpredictable for $10-15 \%$ children.

The current study recorded a significant decline in heart rate and blood-pressure in $\mathrm{H}$ and PMR groups. The present findings are in concordance with that of Oberoi et al. (2016) who noted the decline of pulse rate by 14 after hypnosis. The authors attributed this change to the relaxed state of focused attention created by the hypnosis that masked the physical stimulation of injection. Gokli et al. (1994) found a similar drop-in pulse rate by 4 points in the hypnosis group. Similar findings were found by Ramirez-Carrassco et al. (2017) who found better control of heart rate under hypnosis. Park et al. (2019) found a decrease in pulse rate, blood pressure in patients trained in PMR before periodontal surgery similar to the present study. Due to lack of studies on anxiety parameters for PMR in paediatric dentistry, the findings are a considerable addition to existing knowledge.

Hypoxia may be a side-effect of dental surgery resulting from stress, anxiety, and breath-holding (Amoian et al. 2013). In the present study, it was seen that all 60 children were maintaining high oxygen saturation irrespective of group. These findings are consistent with Oberoi et al. (2016) and Gokli et al. (1994) who concluded that since none of the procedures have any effect on the patient's airway or respiratory efforts, the oxygen saturation remains unchanged. Further, the increased heart rate may be compensatory to maintain saturation levels within the normal range as in the present study (Levy and Mathers 1949).

Pain control was observed to be better in the H and PMR groups whereas marked rise in pain was seen in the control group. Our results were similar to Huet et al. (2011) where visual analog scale and modified objective pain score were used to record pain during dental anaesthesia and lower pain was recorded in the hypnosis group. Peimani et al. (2017) performed a study on oral surgical procedures in adults and found decline in pain when hypnosis was used. Abdeshahi et al. (2013) assessed effects of hypnosis during 3rd molar extraction and found significant reduction in pain after hypnosis. On the contrary, study by Ramirez-Carrassco et al. (2017) during dental procedures in children found no significant differences in pain between hypnosis and control groups. A lack of well-planned studies to assess the effect of PMR on pain/analgesic consumption in the dental practice was found.

The post-operative analgesic requirement was reduced in the hypnosis and PMR groups to the tune of $45 \%$ and $50 \%$ respectively meaning thereby that hypnosis and PMR may have a positive role in post-operative analgesia. This is similar to findings by Abdeshahi et al. (2013) where only $41.7 \%$ of patients in the hypnosis group took analgesic as opposed to $91.7 \%$ of patients in the non-hypnosis group. However, more studies are needed for a better understanding of the area.

Hypnosis is defined as an induced altered state of consciousness characterized by heightened suggestibility and responsivity to the direction (Oberoi et al. 2016). Hypnosis carries great therapeutic benefits in medicine/psychology. In dentistry, hypnosis has potential therapeutic and operative uses such as management of dental phobia, anxiety, behaviour modification, habit modification and analgesia (Allison 2015). Various research proves efficacy in the hands of trained experts (Gokli et al. 1994; Huet et al. 2011; Oberoi et al. 2016) but a large misconception about it exists. Hypnosis lacks popularity due to lack of training, its absence in university curriculum (Milgrom et al. 2009) and many believe its use is time-consuming (Finkelstein 2003). On the contrary, it is economical (Jameson et al. 2007) and devoid of risks (Allison 2015). Moreover, children are more inclined towards hypnosis due to high imaginative capability (Trakyali et al. 2008). However, its present application in paediatric dentistry is limited (Oberoi et al. 2016).

First described by Jacobson (1938), the process of PMR is based on the basic principle of muscle physiology, that when a muscle is tensed, releasing the tension produced relaxation in the muscle creating a state of calmness (Conrad and Roth 2007). The procedure through simple but will require an investment of time by both clinicians and patients (Logan and Marek 2007). This leads to a lack of its use in routine dental practice. PMR has been viewed as a favourable technique for dental anxiety (Appukuttan 2016; Park et al. 2019). So far, its direct implication in paediatric dentistry has not been evaluated to our knowledge. The clinical utility of PMR in busy outpatient dentistry settings is emphasized in the present study after prior operator training. 
The present study was comprehensive involving a multidisciplinary team including mental health professionals. The training of the operator with American Hypnosis Association and under Psychiatry department ensured technique standardization. Moreover, the use of objective parameters confirmed veracity of scales used. The trial limitation includes partial blinding due to the inability of the principal operator to be blinded.

In future, a crossover design may be planned comparing hypnosis and progressive muscle relaxation. The use of other modifications in hypnotic inductions and relaxation techniques may be explored to design a suitable technique adapted for children in the dental setting.

In present times, the COVID-19 virus poses a concern presenting with mild to persistent respiratory tract symptoms post recovery (Carfi et al. 2020). Respiratory distress or congestion may limit the use of conscious sedation which is a pharmacological modality advocated managing anxious or uncooperative paediatric patients (Myles et al. 2004; Vanhee et al. 2020). Moreover, there may be an increased risk of cross-contamination through the circuit which would lead to increased investment for sterilization (Vanhee et al. 2020). Therefore, Hypnosis and Progressive Muscle Relaxation may serve as promising alternatives for the management of anxious children in the years to follow.

\section{Conclusion}

Hypnosis and progressive muscle relaxation may considerably reduce anxiety, heart rate and blood pressure among children receiving local anaesthesia and tooth extractions. Hypnosis and PMR may improve pain control and reduce need for analgesic among children even after noxious procedure such as tooth extraction. The positive effect of both techniques was observed to be comparable. No significant variation in partial pressure oxygen was seen which may be compensated by increased heart rate.

Acknowledgements We would like to acknowledge and thank Dr. A.K. Bansal and Dr. Sukhvinder Singh Oberoi for statistical analysis and support.

Authors contributions PS was the principal investigator for the study and underwent rigorous training in both intervention techniques i.e. Hypnosis and Progressive Muscle Relaxation. PS contributed to the study design and methodology and helped in drafting, revising and proofing the manuscript to its final form. NK contributed to the conception and designing of the study. NK supervised fully the performance of the operator in the study period. NK helped in data interpretation, revising and proofing of the manuscript to be submitted. RT was the evaluator blinded to the study groups during the period of data collection. RT made significant contribution towards the interpretation of results, reviewing literature and approval of the final manuscript. AK contributed to the data acquisition, designing methods and ensured smooth functioning of study settings. AK helped to critically evaluate and revise the final version of the manuscript to be submitted. SS contributed to the conception and design of the study. SS helped to train the operator in hypnosis and Progressive Muscle Relaxation to satisfaction. SS revised the final version of manuscript submitted. As per CREDIT taxonomy, conception and study design: all authors; methodology: PS, NK, RT, SS; formal analysis and investigation: PS, NK, AK, RT; writing —original draft preparation: PS, NK; writing reviewing and editing: PS, NK, RT, AK, SS; funding acquisition: no funding or grant or resources; Supervision: NK, RT, SS. All authors contributed significantly towards the conception and design of the study.

Funding No funding was received to assist with the preparation of this manuscript.

Data availability The principal operator, Puja Sabherwal has complete access to all the data acquired as a part of the study and takes responsibility for the accuracy and integrity of the data. The data may be obtained on contacting the principal investigator.

\section{Declarations}

Conflict of interest The authors have no conflicts of interest to declare that are relevant to the content of this article.

Ethical approval Ethical approval was taken from the Institutional Ethics Committee-IEC-HR/2018/36/133 dated 15/10/2018. The purpose and nature of the study were explained to parents and children. Informed consent was obtained including parental consent and paediatric assent in the native language i.e. Hindi.

Informed consent Informed consent and paediatric assent were obtained from all study participants prior to enrolment.

\section{References}

Abdeshahi SK, Hashemipour MA, Mesgarzadeh V, Shahidi PA, Halaj MA. Effect of hypnosis on induction of local anaesthesia, pain perception, control of haemorrhage and anxiety during extraction of third molars: a case-control study. J Craniomaxillofac Surg. 2013;41(4):310-5.

Al-Harasi S, Ashley PF, Moles DR, Parekh S, Walters V. Hypnosis for children undergoing dental treatment. Cochrane Database Syst Rev. 2010;8:CD007154.

Allison N. Hypnosis in modern dentistry: Challenging misconceptions. Fac Dent J. 2015;6(4):172-5.

Alsheneifi T, Hughes VC. Reasons for dental extractions in children. Pediatr Dent. 2001;23(2):109-12.

Amoian B, Rabíee M, Aghvami M, Milani S. Evaluation of hemodynamic and $\mathrm{SpO}_{2}$ variability during different stages of periodontal surgery. J Indian SocPeriodontol. 2013;17(5):612-6.

Anbar RD. Self-hypnosis for management of chronic dyspnea in pediatric patients. Pediatrics. 2001;107(2):E21.

Appukuttan DP. Strategies to manage patients with dental anxiety and dental phobia: literature review. ClinCosmetInvestig Dent. 2016;8:35-50.

Armfield JM, Heaton LJ. Management of fear and anxiety in the dental clinic: a review. Aust Dent J. 2013;58(4):390-407.

Axelrad AD, Brown D, Wain HJ. Hypnosis. In: Sadock BJ, Sadock VA, Ruiz P, editors. Kaplan \& Sadock's comprehensive textbook of psychiatry. 9th ed. Philadelphia: Lippincott Williams \& Wilkins; 2009. p. 2804-31. 
Baskin TW, Tierney SC, Minami T, Wampold BE. Establishing specificity in psychotherapy: a meta-analysis of structural equivalence of placebo controls. J Consult Clin Psychol. 2003;71:973-9.

Berggren U, Hakeberg M, Carlsson SG. Relaxation vs cognitively oriented therapies for dental fear. J Dent Res. 2000;79(9):1645-51.

Calipel S, Lucas-Polomeni MM, Wodey E, Ecoffey C. Premedication in children: hypnosis versus midazolam. PaediatrAnaesth. 2005;15(4):275-81.

Cao X, Yumul R, Lazo OLE, Friedman J, Durra O, Zhang X, et al. A novel visual facial anxiety scale for assessing preoperative anxiety. PLoS ONE. 2017;12(2):1-7.

Carfì A, Bernabei R, Landi F. Persistent Symptoms in Patients After Acute COVID. JAMA. 2020;324(6):603-5 (Gemelli against covid-19 post-acute care study group).

Chambers DW. Communicating with the young dental patient. J Am Dent Assoc. 1976;93(4):793-9.

Children's Anxiety Institute. How to teach children progressive muscle relaxation. 2018. http://childrenwithanxiety.com/how-to-teachchildren-progressive-muscle-relaxation.html. Accessed 17 June 2018.

Conrad A, Roth WT. Muscle relaxation therapy for anxiety disorders: it works but how? J Anxiety Disord. 2007;21(3):243-64.

Emery CF, France CR, Harris J, Norman G, Vanarsdalen C. Effects of progressive muscle relaxation training on nociceptive flexion reflex threshold in healthy young adults: a randomized trial. Pain. 2008;138(2):375-9.

Faymonville ME, Defechereux T, Joris J, Adant JP, Hamoir E, Meurisse M. Hypnosis and its application in surgery. Rev Med Liege. 1998;53(7):414-8.

Finkelstein S. Rapid hypnotic inductions and therapeutic suggestions in the dental setting. Int J Clin Exp Hypn. 2003;51(1):77-85.

Glaesmer H, Geupel H, Haak R. A controlled trial on the effect of hypnosis on dental anxiety in tooth removal patients. Patient Educ Couns. 2015;98(9):1112-5.

Gokli MA, Wood AJ, Mourino AP, Farrington FH, Best AM. Hypnosis as an adjunct to the administration of local anesthetic in pediatric patients. ASDC J Dent Child. 1994;61(4):272-5.

Huet A, Lucas-Polomeni MM, Robert JC, Sixou JL, Wodey E. Hypnosis and dental anesthesia in children: a prospective controlled study. Int J Clin Exp Hypn. 2011;59(4):424-40.

Jacobson E. Progressive relaxation. Chicago: University of Chicago Press; 1938.

Jameson K, Averley PA, Shackley P, Steele J. A comparison of the 'cost per child treated' at a primary care-based sedation referral service, compared to a general anaesthetic in hospital. Br Dent J. 2007;203(6):E13.

Karasu TB, Karasu SR. Psychoanalysis and psychoanalytic psychotherapy. In: Sadock BJ, Sadock VA, Ruiz P, editors. Kaplan \& Sadock's Comprehensive Textbook of Psychiatry. 9th ed. Philadelphia: Lippincott Williams \& Wilkins; 2009. p. 2787-8.

Klaassen MA, Veerkamp JS, Hoogstraten J. Changes in children's dental fear: a longitudinal study. Eur Arch Paediatr Dent. 2008;9(Suppl 1):29-35.
Kohen DP, Olness K. Hypnosis and hypnotherapy with children. 4th ed. New York: Routledge; 2011.

Levy RL, Mathers JA. Relationship between the oxygen $\mathrm{n}$ saturation of the blood and changes in the electrocardiogram, blood pressure and heart rate during induced anoxemia: Observations on normal persons and patients with suspected and manifest coronary heart disease. Trans Am Clin Climatol Assoc. 1949;61:50-64.

Logan H, Marek C. The anxious or fearful dental patient. In: Stefanac SJ, Nesbit SP, editors. Treatment planning in dentistry. 1st ed. St Louis: Mosby Elsevierpp; 2007. p. 339-65.

Milgrom P, Weinstein P, Heaton LJ. Treating fearful dental patients: a patient management handbook. 3rd ed. Seattle : Dental Behavioral Resources; 2009.

Montgomery P, Grant S, Mayo-Wilson E, Macdonald G, Michie S, Hopewell S, et al. Reporting randomised trials of social and psychological interventions: the CONSORT-SPI 2018 extension. Trials. 2018;19(1):407.

Myles PS, Leslie K, Silbert B, Paech M, Peyton P. A review of the risks and benefits of nitrous oxide in current anaesthetic practice. Anaesth Intensive Care. 2004;32:165-72.

Oberoi J, Panda A, Garg I. Effect of hypnosis during administration of local anesthesia in six to 16 year old children. Pediatr Dent. 2016;38(2):112-6.

Park ES, Yim HW, Lee KS. Progressive muscle relaxation therapy to relieve dental anxiety: a randomized controlled trial. Eur J Oral Sci. 2019;127:45-51.

Peimani A, Irannezhad M, Ahmadi MA. Comparing the effect of hypnosis and local anesthesia injection on induction of local anesthesia, anxiety, hemorrhage and pain control during tooth extraction. J Res Med Dent Sci. 2017;5(4):44-9.

Ramírez-Carrasco A, Butrón-TéllezGirón C, Sanchez-Armass O, Pierdant-Pérez M. Effectiveness of hypnosis in combination with conventional techniques of behavior management in anxiety/pain reduction during dental anesthetic infiltration. Pain Res Manag. 2017;2017:1434015.

Trakyali G, Sayınsu K, Müezzinoğlu AE, Arun T. Conscious hypnosis as a method for patient motivation in cervical headgear wear-a pilot study. Eur J Orthod. 2008;30(2):147-52.

Vanhee T, Lachiri F, Van Den Steen E, Bottenberg P, Vanden AA. Child behaviour during dental care under nitrous oxide sedation: a cohort study using two different gas distribution systems. Eur Arch Paediatr Dent. 2020. https://doi.org/10.1007/s40368-020-00569-z.

Wong DL, Baker CM. Pain in children: comparison of assessment scales. Pediatr Nurs. 1988;14(1):9-17.

Zanette G, Robb N, Facco E, Zanette L, Manani G. Sedation in dentistry: current sedation practice in Italy. Eur J Anaesthesiol. 2007;24(2):198-200.

Publisher's Note Springer Nature remains neutral with regard to jurisdictional claims in published maps and institutional affiliations. 